Special issue of the International Conference on Computational and Experimental Science and Engineering (ICCESEN 2014)

\title{
Failure Analysis of a Lower Wishbone
}

\author{
A. RutCI* \\ Teknorot Automotive Product İndustry, Research-Development Center, Düzce, Turkey
}

\begin{abstract}
It is known that wishbone is a hinged suspension link between the chassis and the suspension hub that carries the wheel. This paper describes the failure analysis of a lower wishbone (control arm) in a light commercial vehicle which had been involved in service loading. The wishbone was analyzed in two ways. In order to investigate reason of the failure, finite element modelling was conducted to evaluate stress distribution and reliability of wishbone. Moreover, the metallographic and hardness evaluation were made on weld seam of the failed part. From metallographic observations, the presence of porosity was found in weld seam. Hardness distributions from the parent material to weld region are measured in the expected range. The results of finite element analysis and metallographic examination showed that the fatigue failure was initiated from highly stressed region in weld seam, and the presence of porosity stimulated crack initiation as well as crack growth.
\end{abstract}

DOI: 10.12693 /APhysPolA.128.B-75

PACS: $81.40 . \mathrm{Np}$

\section{Introduction}

It is known that the purpose of suspension system is to reduce vertical and longitudinal wheel load variations like that bumps and vibrations of the vehicle body. Moreover, suspension system provides that when a vehicle drives on an uneven road surface, the suspension links are in constant motion and keeps to rolling movement as minimum on the road bend.

Lower control arm (Fig. 1) is one of the most important suspension parts of vehicle body that enables the wheel to keep its desired position and provides upwards and downwards movement of the wheel in safety.

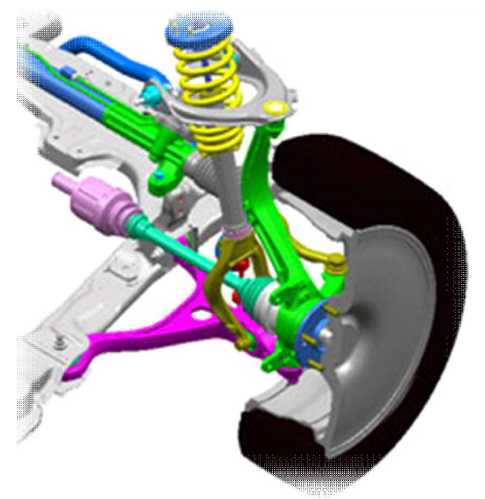

Fig. 1. Lower wishbone painted purple.

Another important role of the suspension system is to compensate forces that occur as a result of the accelerations of the car. Besides, it makes the vehicle more comfortable and safer. Forces that occur as a result of accelerations, breaking and rolling movement of the vehicle,

\footnotetext{
*e-mail: alimurtaza.rutci@teknorot.com
}

are compensated by bearing mounted on vehicle chassis. Movement tends of the lower control arm are absorbed by bushes which are made of rubber. Also rubber bushings provide a connection between the suspension link and the vehicle's body with a degree of rotational freedom, whose material is rubber.

The role of the lower control arm becomes critical because of the exposing variable forces when the vehicle is on the road. As a result, the lower control arm which is the part of suspension system has a significant effect on vehicle dynamics.

Variable forces may lead the fatigue fracture on parent body and connection region weld seam (Fig. 2). During movement of the vehicle, fracture of lower control arm inflict heavy damage economically and vitally.

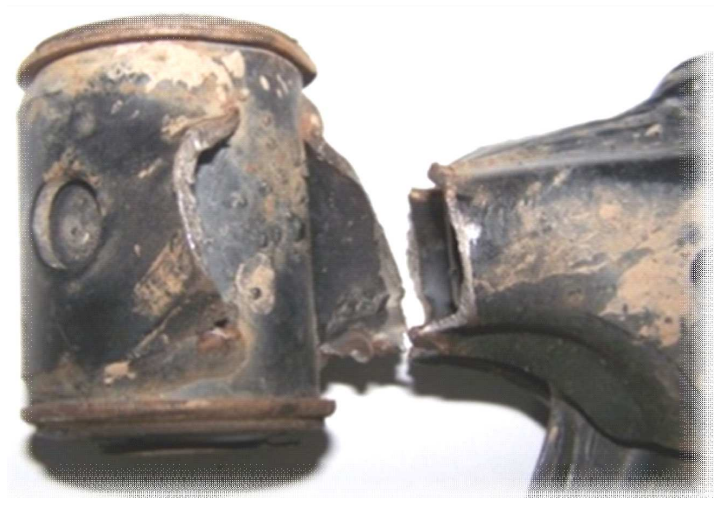

Fig. 2. Failure wishbone.

In this study, there is an explanation to investigate reason of the failure analysis of a lower wishbone (control arm) in a light commercial vehicle of the failure that has developed in Teknorot R\&D Center. Optical microscope studies lead us to investigation of the failure analysis of a lower control arm. These studies are aimed to find the cause of failure fracture. 


\section{Experimental study}

The lower control arm has been manufactured with sheet forming and welded with metal active gas (MAG) welding. All of our developed products have been tested by fatigue test bench which is located in $R \& D$ Center (Fig. 3). According to fatigue test results, the lower control arm has not ensured desired performance repeatedly. With applied loading on the lower control arm, fracture failure has detected lower cycles than we expected. All of experimental studies show us that fracture region has not changed.

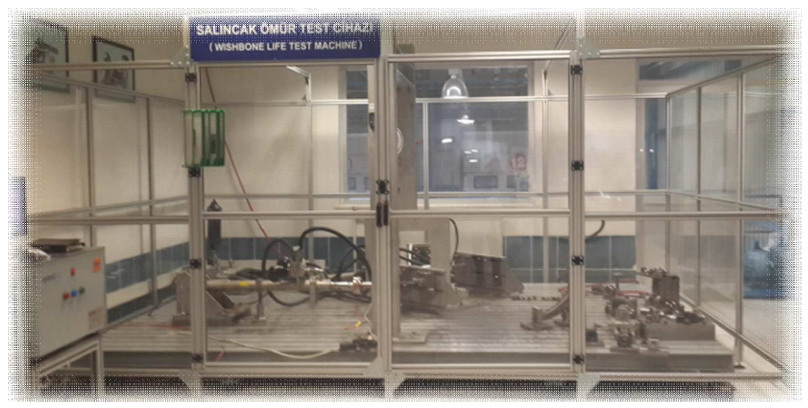

Fig. 3. Fatigue test bench.

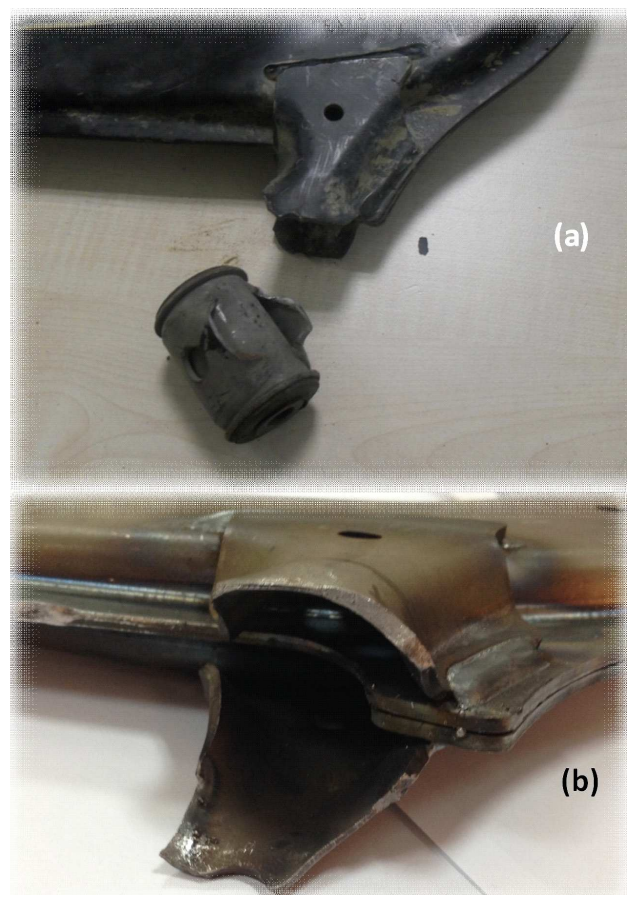

Fig. 4. Failed wishbone after fatigue test.

As seen on the photo (Fig. 4) fracture region is the same. It is important that crack fracture has started beginning from the weld seam and connection area bush tube between bracket.

In this experimental study, sheet metal has been prepared to analyze microstructure of lower control arm from area fracture region and connecting area.

\section{Results and discussion}

Figure 5 shows the microstructure of sheet metal used in manufacturing of wishbone. Analysis shows that the microstructure of the sheet metal is ferritic steel.

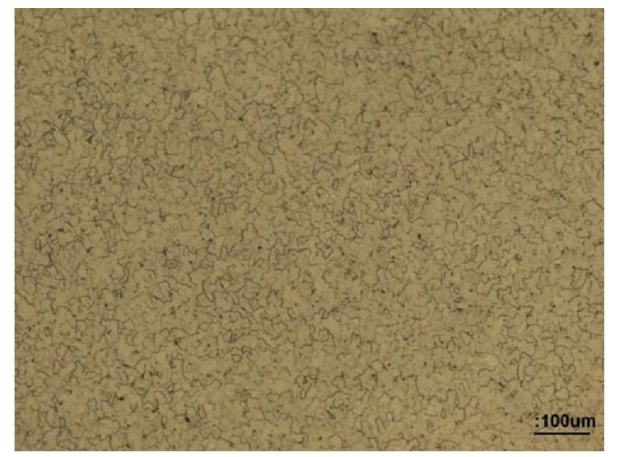

Fig. 5. Microstructure of sheet metal used in manufacturing of wishbone.

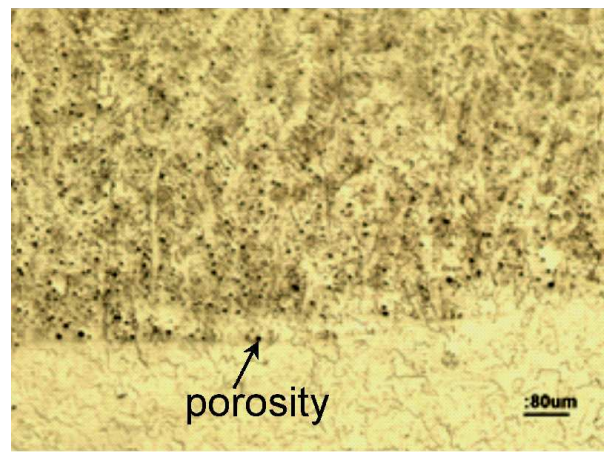

Fig. 6. Microstructure of weld junction region.

Base metal and welding metal is given in Fig. 6 and examined together, it is noticed that the gas gap is located in the welding area. Especially in the base metal and welding metal transition areas show the concentrations of the gas gap significantly. It is known that the formation of gas gap is related to the inability of the gas mixture amount [1]. Taking into consideration that the prototype used in the gas mixture flow is inadequate for the formation of porosity, the experiment of welding is made by increasing the gas flow.

Investigating reason of the failure, finite element (FE) modelling was conducted to evaluate stress distribution that shows us that fracture starts from the some region within lower cycles than we desired (Fig. 7). Inferring from this study, porosity causes the fracture on the weld seam.

As it is known that the porosity on weld seam increases the stress concentration and thus porosity leads to increase of stress value locally. If porosity area corresponds to a point on the outer notch or an area on the notch, it is easy to show up the effects on it. With experiments and evaluations, the microstructures porosity (Fig. 8) level was appropriate. The welding conditions have the most suitable value for this study. After the test of prototypes 


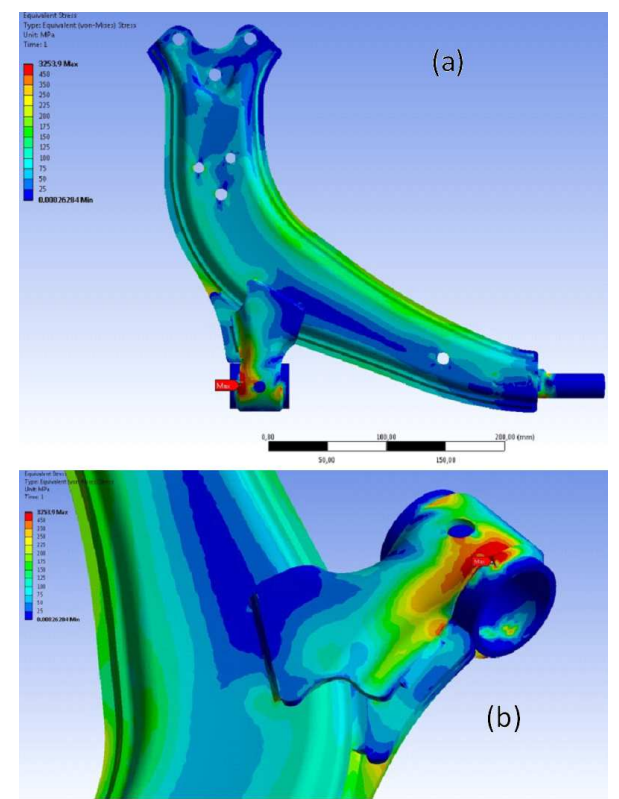

Fig. 7. (a) General stress (Von Mises) distribution of wishbone subjected to test loading, (b) detailed appearance [2].

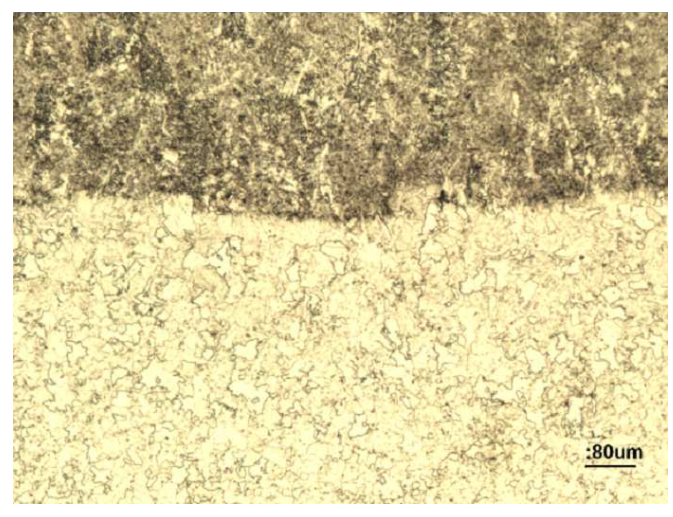

Fig. 8. Weld junction region for the parts welded appropriate gas flow.

which includes all the three samples which were tested, the fatigue life increase of those parts's porosity probability was blocked.

\section{Conclusion}

Although the welding of the gas mixture is suitable, the welding area cannot be sent to a sufficient quantity of the gas mixture which leads to the cause of undesirable porosity. Metallographic examination of the welding seam gas gaps that may develop under dynamic stress to accelerate the formation of fatigue cracks in part, in a sense, it was found that the formation of cracks increases the sensitivity.

\section{References}

[1] Metals Handbook, Welding, Brazing, and Soldering, Metals Park, Ohio 2006.

[2] Improvement of sheet metal wishbone, R\&D Center Improvement Project, Teknorot A.Ş., 2013 (in Turkish).

[3] R.İ. Stephens, A. Fatemi, R.R. Stephens, H.O. Fuchs, Metal Fatigue in Engineering, 2nd ed., Wiley, New York 2001. 